10.2478/genst-2018-0010

\title{
ALCOHOL CONSUMPTION AMONG GHANAIAN WOMEN OF CHILD BEARING AGE - WHAT ARE THE CORRELATES?
}

\section{EDWARD NKETIAH-AMPONSAH}

Department of Economics

University of Ghana

Legon Boundary, Accra, Ghana

enamponsah@ug.edu.gh

\section{GLORIA AFFUL-MENSAH}

Department of Economics, Management and Quantitative Methods

University of Milan, Italy

Via Festa del Perdono, 7, 20122 Milan

gaffulmensah@yahoo.com

SAMUEL AMPAW

Department of Economics

University of Ghana

Legon Boundary, Accra

samie.ampaw@yahoo.com

\section{EMMANUEL CODJOE}

Department of Economics

University of Ghana

Legon Boundary, Accra

ecodjoe@gmail.com

Abstract: This paper examines the demographic and socio-economic correlates of alcohol consumption and drinking frequency among Ghanaian women aged 15-49 years. The study utilizes the 2008 Ghana Demographic and Health Survey data, which remains the most recent DHS for studying the phenomenon in 
Ghana. Using logistic regression, our findings indicate that alcohol consumption among Ghanaian women is influenced by age, education, and wealth status. In addition, while health insurance ownership significantly affects alcohol consumption among urban women, employment status is reported to be a significant determinant among rural women. Results from the ordered logistic regression show that age, wealth status, pregnancy status, and place of residence are significant predictors of alcohol drinking frequency among Ghanaian women. Moreover, while secondary educational attainment is significant among urban women, primary educational attainment is significant among rural women. The study concludes that the predictors of alcohol consumption and drinking frequency among women of childbearing age in Ghana vary by place of residence (i.e., rural vs urban).

Keywords: alcohol consumption, alcohol drinking frequency, women of reproductive age, logit regression, ordered logit regression, rural/urban Ghana.

\section{Introduction}

The health burden associated with the consumption of alcohol both in terms of morbidity and mortality is obvious (Cheah and Rasiah, 2017). Frequent consumption of alcohol to intoxication level may lead to increased probability of fatalities through accidents. People who frequently drink to intoxication levels may also absent themselves from work and this may affect productivity at both the micro and macro levels. In addition, excessive in-take of alcohol may incite people to engage in violent and crime-related activities culminating in various degrees of injuries and in some cases deaths.

Yet, alcohol consumption is pervasive in many countries. The world's highest consumption rates occur mostly in the developed countries, particularly Eastern and Western Europe. In Africa, the highest consumption rates are recorded in the southern part with South Africa and Namibia having the highest consumption levels. Likewise, the increasing participation of the youth and women in alcohol consumption is a matter of concern for health policy makers (Kim \& Kim, 2008). Martinez et al. (2011) underscored the increasing prevalence of alcohol use by women in African countries such as Botswana (30\%) and Namibia (47\%) (see also McDermott et al., 2009). It is estimated that $18 \%$ of women of childbearing age (15-49 years) in Ghana drink alcoholic beverages (GSS, 2009). Due to the increasing prevalence of alcohol consumption, all the 193 WHO Member States endorsed a global strategy to reduce the harmful use of alcohol in 2010 (WHO, 2011).

In Ghana, alcohol consumption is increasingly becoming a major public health concern. Although the existing consumption level of 1.54 litres yearly seems relatively low, it poses one of 
the highest risk factors for deaths and disability in the country (GSS, 2009). This is because the reported level of consumption obviously does not include those consumed surreptitiously due to the prevalence of traditional alcoholic beverages in Ghana; and this possibly represent a larger share of alcohol consumption. However, there is lack of consistent data on alcohol consumption pattern in terms of type consumed, the quantity consumed and frequency of consumption to inform rigorous studies. This necessitated the need to collect consistent information on alcohol consumption in the 2008 Ghana Demographic and Health Survey (GDHS). While available statistics on alcohol consumption in Ghana may seem relatively low compared to other countries in Africa, there is a disturbing trend of increasing consumption of especially the locally brewed alcoholic beverages among females. The type of alcohol usually consumed ranges from beer, spirits, wine, and other locally brewed alcoholic beverages. In Ghana, while pito (a fermented alcoholic beverage made from millet) is most commonly consumed in the northern part of the country, in the southern part, it is palm wine and/or akpeteshie (mostly distilled from palm wine). In addition, there is an upward trend for adolescent participation even though the minimum age for drinking alcohol in Ghana is eighteen (18) years. Nonetheless, there is no age limit for on and off purchasing of alcohol in Ghana coupled with the fact that there is no enforcement of the age limit for alcohol consumption.

Despite all the health and social problems associated with the abuse of alcohol, there is scant literature on consumption patterns and its socio-economic and demographic correlates. Given the relatively more adverse effects of excessive drinking on females compared to males due to their biological composition and coupled with the fact that female participation with respect to alcohol consumption in Ghana is increasing, this paper attempts to ascertain the key correlates of alcohol consumption and its frequency among urban and rural Ghanaian women (aged between 15 and 49 years). The paper focuses on women because of the role women play typically in Ghanaian households in terms of raising young-ones and so they are more likely to influence these young ones with any risky health behaviours they associate themselves with.

\section{Related Literature}

Grossman (1972) emphasizes the role of education in an individual's demand for healthrelated goods. Higher education is expected to result in less alcohol consumption (see also Perkings, 2002; Rintaugu et al. 2012; Kacapyr and Choudhury, 2006). Other studies have espoused the role of religious beliefs and other socio-economic attributes in alcohol consumption behavior 
(Brown et al. 2001; Barros et al 2009; Martinez et al. 2011; Adeyiga et al, 2014). For instance, Brown et.al (2001) revealed that boys from very religious groups consumed less alcohol than their counterparts who are not very religious in the USA. Also, Dumbili (2013); Luginaah and Dakubo (2003); Martinez et al. (2011) have shown higher prevalence of alcohol use among women within lower income groups in Africa. Furthermore, working women, especially those who work outside the home, are found to be more likely to consume alcohol than their non-working counterparts. Dawson et al. (2005); Seaman and Ikeguowu (2010) further reported that women adopt the drinking patterns of men because they want to bridge the gender gap as well as reduce stress.

Newbury-Birch et al. (2009) found that while good family relations act as protective factor to decrease the probability of an individual drinking, poor relations may increase this probability. Also, a study by O'Malley and Wagenaar (1991) revealed that setting a higher minimum drinking age leads to lower consumption rates among high school seniors in the USA. Mbatia et al. (2009) reported that hazardous alcohol use is prevalent among never-married women. Additionally, Adusi-Poku et al. (2013) found that alcohol use is more prevalent among pregnant married women in Bosomtwe District (Ghana) than their unmarried counterparts.

A more recent study on Ghana explored the factors associated with alcohol consumption among a cross-section of women of child bearing age (Adeyiga et al. 2014). The study was however limited to women attending clinics of the Department of Obstetrics and Gynecology outpatient at the Korle Bu Teaching Hospital in Accra. Also, Anyawie (2013) investigated the determinants of alcohol consumption among women in three communities in Ghana using logit regression. While this was an informative study, the model omitted important covariates such as education and income/wealth, which in the absence of price are considered significant predictors of alcohol consumption. Besides, the study was limited to only three communities and thus results cannot be generalized to the Ghanaian population. The current study rather uses a nationally representative survey, the findings of which could be generalized to the population. Although this study is similar to Tampah-Naah and Amoah (2015), the contribution of this paper lies in the analysis of the results from a rural-urban perspective and the focus on women in the reproductive age bracket.

\section{Methodology}

\subsection{Method of Analysis}


This study employs two models to identify the factors influencing alcohol consumption and its frequency among Ghanaian women of reproductive age. In the first model, alcohol consumption is modelled as a binary variable; whether or not a woman consumes alcohol over the past 7 days preceding the survey. Here, the dependent variable takes the value of 1 if the respondent consumed alcohol and 0 otherwise. Since the dependent variable is dichotomous, the logit or probit models can be used by employing maximum likelihood procedure to estimate the parameters. In this study, the probability that a woman consumes alcohol can be written as $\operatorname{Pr}\left(Y_{i}=1\right)$ if she consumes alcohol. It is assumed that the woman will weigh the utility to be derived from consumption of alcohol relative to the utility without such consumption. The woman takes a decision to consume provided the utility associated with its consumption is higher than the utility without consumption.

In the second model, the correlates of alcohol consumption frequency, the dependent variable is the number of times alcohol was consumed within a week. It is a categorical variable given as a range $(0,1,2-3$ times, 4 times or more). Thus, the dependent variable is polychotomous, there is a natural ordering; $0=$ none, $1=$ once, $2=2-3$ times, and $3=4$ times or more, hence multinomial logit is used to estimate the model.

The socio-economic characteristics considered in the model are educational level, wealth index, employment status, place of residence, health insurance ownership, and relationship to head, pregnancy status, and age. The choice of these variables is influenced by both theoretical and empirical literature. For instance, the place of residence (rural or urban) was included in order to determine whether or not living in the rural area (where most households are economically deprived) may influence the consumption of alcohol. However, based on the bivariate analysis, the variables which are statistically insignificant $(p>0.05)$ were excluded from either the logit regression and or ordered logit regression.

\subsection{Source of Data and its Limitations}

Out of the six rounds of the Demographic and Health Surveys, only the 2008 GDHS collected some relatively detailed information on the consumption of alcohol in Ghana. Hence, the study relies on the 2008 GDHS. The 2008 GDHS is a national household-based survey covering all the ten regions in Ghana. It is the fifth of its kind with other surveys conducted in 1988, 1993, 1998, 2003, and 2014. The 2008 GDHS was primarily carried out by the Ghana Statistical Service and the Ghana Health Service. The survey used two-stage sample which is based on the 2,000 
Population and Housing Census to produce separate estimates for each region in Ghana (GDHS Report, 2008). In all, a total of 11,778 households were interviewed; 4,916 women between 15 and 49 years and 4,568 men, aged 15-59 years were interviewed. This study is however based on the women's questionnaire.

The survey therefore contains detailed information on variables including inter alia fertility preferences, family planning (awareness, knowledge and use of methods), maternal health (antenatal care, delivery care, postnatal care, etc.), child health (nutrition, mortality, etc.), HIV/AIDS (awareness and behaviour) and other sexually transmitted infections. The ICF MACRO assisted the implementation of the survey financially and technically through the MEASURE DHS Programme funded by USAID. This programme is designed to help developing countries with regard to collecting data on fertility, family planning and maternal and child health. The data was collected between September and November 2008. While the 2008 GDHS happens to be one of the best data for such a study, it does not contain certain information on some variables like price of the alcoholic drink, type of drink consumed and income of the respondent which may be very important for such a study. However, with regard to income, the data uses wealth index (measured in quintiles) as a proxy. Table 1 presents description and measurement of the variables employed for the analysis.

Table 1: Description and Measurements of Variables used in the Estimations

\begin{tabular}{|c|c|c|}
\hline Variable & Description & Measurement \\
\hline $\begin{array}{l}\text { Drinks } \\
\text { Drinking frequency }\end{array}$ & $\begin{array}{l}\text { Outcome Variable } \\
\text { alcohol drinking status } \\
\text { Times consumed alcohol in last } 7 \\
\text { days } \\
\text { Explanatory Variables }\end{array}$ & $\begin{array}{l}1=\text { drinks, } 0=\text { otherwise } \\
0=\text { none, } 1=\text { once, } 2=\text { few }(2-3 \\
\text { times }), 3=\text { more }(4 \text { times or more })\end{array}$ \\
\hline Age & Age of respondent & Measured in years \\
\hline Age square & Square of respondent's age & Square of age \\
\hline Health insured & Health insurance status & $1=$ insured, $0=$ uninsured \\
\hline Relationship to head & Relationship to household head & $1=$ head, $0=$ otherwise \\
\hline Employed & Employment status & $1=$ employed, otherwise $=0$ \\
\hline Urban & Type of place of residence & $1=$ urban, $0=$ rural \\
\hline Pregnant & Pregnancy status & $1=$ currently pregnant, $0=$ otherwise \\
\hline Poorest & Wealth quintile & $1=$ poorest, otherwise $=0$ \\
\hline Poorer & Wealth quintile & $1=$ poorer, otherwise $=0$ \\
\hline Middle & Wealth quintile & $1=$ average, otherwise $=0$ \\
\hline Richer & Wealth quintile & $1=$ richer, otherwise $=0$ \\
\hline Richest & Wealth quintile (omitted) & $1=$ richest , otherwise $=0$ \\
\hline No education & Educational attainment (omitted) & $1=$ no education, otherwise $=0$ \\
\hline Primary education & Educational attainment & $1=$ primary, otherwise $=0$ \\
\hline Secondary education & Educational attainment & $1=$ secondary, otherwise $=0$ \\
\hline Tertiary education & Educational attainment & $1=$ tertiary, otherwise $=0$ \\
\hline
\end{tabular}




\section{Results \\ 4.1 Descriptive Statistics}

According to the 2008 GDHS report, alcohol consumption varies by background characteristics (gender, age, place of residence, education, etc). The descriptive statistics of the variables are reported in Table 2. It is reported that $19.49 \%$ of the women sampled for the analysis, consumed alcohol. However, more of the women in the rural subsample $(21.78 \%)$, relative to the urban subsample (16.59), consumed alcohol. Moreover, the consumption of alcohol in the last seven days reduces from $37.1 \%$ for those who consumed it once to $8.77 \%$ for those who consumed it more than four times.

\begin{tabular}{|c|c|c|c|}
\hline $\begin{array}{l}\text { Explanatory } \\
\text { Variable }\end{array}$ & Full Sample $(n=4,854)$ & Urban Subsample $(n=2,140)$ & Rural Subsample $(n=2,714)$ \\
\hline \multicolumn{4}{|l|}{ Alcohol Consumption } \\
\hline Yes & 19.49 & 16.59 & 21.78 \\
\hline No & 80.51 & 83.41 & 78.22 \\
\hline \multicolumn{4}{|c|}{ Alcohol Consumption Frequency } \\
\hline None & 28.33 & 43.94 & 18.95 \\
\hline Once & 37.1 & 36.62 & 37.39 \\
\hline $2-3$ times & 25.79 & 14.93 & 32.32 \\
\hline 4 times or more & 8.77 & 4.51 & 11.34 \\
\hline \multicolumn{4}{|l|}{ Age of respondent } \\
\hline Age & 29.00 & 28.64 & 29.29 \\
\hline Age square & 935.03 & 909.39 & 955.24 \\
\hline \multicolumn{4}{|c|}{ Health insurance policy holder } \\
\hline Yes & 41.8 & 45.89 & 38.58 \\
\hline No & 58.2 & 54.11 & 61.42 \\
\hline \multicolumn{4}{|c|}{ Relationship to Household Head } \\
\hline Head & 21.32 & 25.42 & 18.09 \\
\hline Other & 78.68 & 74.58 & 81.91 \\
\hline \multicolumn{4}{|l|}{ Currently Working } \\
\hline Yes & 75.22 & 70.7 & 78.78 \\
\hline No & 24.78 & 29.3 & 21.22 \\
\hline \multicolumn{4}{|l|}{ Place of residence } \\
\hline Urban & 44.09 & & \\
\hline Rural & 55.91 & & \\
\hline \multicolumn{4}{|l|}{ Currently Pregnant } \\
\hline Yes & 7.48 & 6.50 & 8.25 \\
\hline No & 92.52 & 93.5 & 91.75 \\
\hline \multicolumn{4}{|l|}{ Wealth Quintile } \\
\hline poorest & 21.98 & 1.17 & 38.39 \\
\hline Poorer & 18.79 & 5.14 & 29.55 \\
\hline Middle & 18.34 & 18.46 & 18.24 \\
\hline Richer & 20.87 & 34.39 & 10.21 \\
\hline Richest & 20.02 & 40.84 & 3.61 \\
\hline \multicolumn{4}{|l|}{ Educational attainment } \\
\hline No education & 25.18 & 12.34 & 35.30 \\
\hline Primary education & 20.46 & 15.98 & 23.99 \\
\hline Secondary education & 50.68 & 64.95 & 39.43 \\
\hline Tertiary education & 3.69 & 6.73 & 1.29 \\
\hline
\end{tabular}

Notes: All, but age, are in proportions

Similar trends were revealed considering the rural and urban subsamples. More women (11.34\%) in the rural subsample consumed alcohol beyond three times in the past week than women 
in the urban subsample (4.51\%). The average age of the women sampled is approximately 29 years. Less than $50 \%$ of the women sampled owned health insurance policies while less than $10 \%$ were pregnant. Most households were headed by someone else $(78.68 \%)$ other than the women themselves (21.32) but majority of the women sampled (75.22\%) were employed. More women (55.91\%) resided in the rural areas than in the urban areas $(44.09 \%)$. With regard to wealth, a little over one-third of the women were in the poorest category with very few of them $(3.61 \%)$ being classified in the richest wealth quintile considering the rural subsample, the reverse is true for the urban subsample. Although more of the women interviewed $(74.82 \%)$ had some form of formal education, the percentage of educated women with respect to the urban subsample $(87.66 \%)$ outweighs that of the rural subsample $(64.70 \%)$.

Since the pregnancy status variable is insignificantly related to alcohol consumption (see Table 3), it is the only variable which is excluded from the logit regression estimation of the determinants of alcohol consumption. Similarly, health insurance ownership and relationship to household head variables were excluded from the ordered logit regression estimation of the frequency of alcohol consumption given that they are insignificant at the conventional 5 percent level of significance. 
Table 3: Bivariate Analysis of variables of concern (Full Sample)

\begin{tabular}{|c|c|c|c|c|c|c|c|c|}
\hline \multirow[t]{2}{*}{ Explanatory Variable } & \multicolumn{3}{|c|}{ Alcohol Consumption } & \multicolumn{4}{|c|}{ Frequency of Consumption } & \multirow[b]{2}{*}{ P-value } \\
\hline & no & yes & P-value & none & once & few & more & \\
\hline Health insurance & & & 0.009 & & & & & 0.758 \\
\hline No & 46.13 & 12.07 & & 17.86 & 22.41 & 15.86 & 5.81 & \\
\hline Yes & 34.38 & 7.42 & & 10.47 & 14.69 & 9.94 & 2.96 & \\
\hline Relationship to Househo & old Head & & 0.000 & & & & & 0.086 \\
\hline Other & 64.19 & 14.48 & & 19.98 & 29.28 & 18.82 & 6.24 & \\
\hline Head & 16.32 & 5.01 & & 8.35 & 7.82 & 6.98 & 2.54 & \\
\hline Currently Working & & & 0.000 & & & & & 0.010 \\
\hline $\begin{array}{l}\text { No } \\
21.96\end{array}$ & & 2.82 & & 5.07 & 6.13 & 2.75 & 0.53 & \\
\hline Yes & 58.55 & 16.67 & & 23.26 & 30.97 & 23.04 & 8.25 & \\
\hline Place of residence & & & 0.000 & & & & & 0.000 \\
\hline $\begin{array}{l}\text { Rural } \\
43.74\end{array}$ & & 12.18 & & 11.84 & 23.36 & 20.19 & 7.08 & \\
\hline Urban & 36.77 & 7.31 & & 16.49 & 13.74 & 5.60 & 1.69 & \\
\hline Currently Pregnant & & & 0.353 & & & & & 0.046 \\
\hline $\begin{array}{l}\text { No } \\
74.35\end{array}$ & & 18.17 & & 25.58 & 34.78 & 24.21 & 8.67 & \\
\hline Yes & 6.16 & 1.32 & & 2.75 & 2.33 & 1.59 & 0.11 & \\
\hline Wealth Quintile & & & 0.000 & & & & & 0.000 \\
\hline Poorest & 15.53 & 6.45 & & 4.44 & 14.16 & 11.21 & 3.28 & \\
\hline Poorer & 15.51 & 3.28 & & 2.75 & 5.29 & 5.81 & 2.96 & \\
\hline Middle & 15.82 & 2.51 & & 5.29 & 3.91 & 2.64 & 1.06 & \\
\hline Richer & 17.82 & 3.05 & & 6.03 & 5.92 & 2.85 & 0.85 & \\
\hline richest & 15.82 & 4.20 & & 9.83 & 7.82 & 3.28 & 0.63 & \\
\hline Educational attainment & & & 0.000 & & & & & 0.000 \\
\hline No education & 18.46 & 6.72 & & 5.07 & 13.85 & 11.84 & 3.70 & \\
\hline Primary education & 16.42 & 4.04 & & 4.76 & 7.19 & 5.60 & 3.17 & \\
\hline Secondary education & 42.75 & 7.93 & & 16.81 & 14.59 & 7.61 & 1.69 & \\
\hline tertiary_education & 2.88 & 0.80 & & 1.69 & 1.48 & 0.74 & 0.21 & \\
\hline
\end{tabular}

\subsection{Logit and Ordered Logit Regression Models}

Table 4 presents the results from the logit and ordered logit regression models for the correlates of alcohol consumption and drinking frequency respectively among Ghanaian women (aged between 15 and 49 years). In addition to the full sample, separate estimations were performed for the rural and urban sub-samples. From both regression models, logit and ordered logit, age, wealth status and educational attainment are reported to be significant correlates of alcohol consumption and its frequency among Ghanaian women. Additionally, though employment status, health insurance status, and relationship to head were found to be important predictors of alcohol consumption, pregnancy status and place of residence are reported to be other significant variables affecting the frequency of consuming alcohol. 


\begin{tabular}{|c|c|c|c|c|c|c|}
\hline \multirow{2}{*}{$\begin{array}{l}\text { Explanatory } \\
\text { Variables }\end{array}$} & \multicolumn{3}{|c|}{ Logit Model } & \multicolumn{3}{|c|}{ Ordered Logit } \\
\hline & Full & Urban & Rural & Full & Urban & Rural \\
\hline \multicolumn{7}{|c|}{ Educational status (no education) } \\
\hline Primary education & $\begin{array}{c}0.0674 \\
(0.1436)\end{array}$ & $\begin{array}{c}0.8001 * * * \\
(0.2832)\end{array}$ & $\begin{array}{l}-0.1659 \\
(0.1731)\end{array}$ & $\begin{array}{c}0.2653 \\
(0.2256)\end{array}$ & $\begin{array}{l}-0.5369 \\
(0.4111)\end{array}$ & $\begin{array}{c}0.5702 * * \\
(0.2763)\end{array}$ \\
\hline Secondary education & $\begin{array}{l}-0.0073 \\
(0.1237)\end{array}$ & $\begin{array}{c}0.7604 * * * \\
(0.2471)\end{array}$ & $\begin{array}{c}-0.3549 * * \\
(0.1598)\end{array}$ & $\begin{array}{l}-0.3203 \\
(0.2146)\end{array}$ & $\begin{array}{c}-0.7748 * * \\
(0.3573)\end{array}$ & $\begin{array}{l}-0.2848 \\
(0.2774)\end{array}$ \\
\hline Tertiary education & $\begin{array}{l}-0.2006 \\
(0.2799)\end{array}$ & $\begin{array}{c}0.3642 \\
(0.3790)\end{array}$ & $\begin{array}{c}0.1869 \\
(0.5368)\end{array}$ & $\begin{array}{l}-0.0177 \\
(0.4380)\end{array}$ & $\begin{array}{l}-0.7584 \\
(0.6105)\end{array}$ & $\begin{array}{c}0.7963 \\
(0.5996)\end{array}$ \\
\hline \multicolumn{7}{|c|}{ Wealth Status (Richest) } \\
\hline Poorest & $\begin{array}{l}-0.1548 \\
(0.2057)\end{array}$ & $\begin{array}{l}-0.9701 \\
(0.8486)\end{array}$ & $\begin{array}{l}-0.2887 \\
(0.3026)\end{array}$ & $\begin{array}{c}0.5580 \\
(0.3382)\end{array}$ & $\begin{array}{c}0.0714 \\
(0.3960)\end{array}$ & $\begin{array}{c}0.6807 \\
(0.5759)\end{array}$ \\
\hline Poorer & $\begin{array}{c}-0.6202 * * * \\
(0.1855)\end{array}$ & $\begin{array}{l}-0.4874 \\
(0.3207)\end{array}$ & $\begin{array}{c}-0.6751 * * \\
(0.3008)\end{array}$ & $\begin{array}{l}1.0201 * * * \\
(0.3328)\end{array}$ & $\begin{array}{c}1.0824 \\
(0.8166)\end{array}$ & $\begin{array}{l}1.1184 * * \\
(0.5645)\end{array}$ \\
\hline Middle & $\begin{array}{c}-0.7565 * * * \\
(0.1654)\end{array}$ & $\begin{array}{c}-0.6182 * * * \\
(0.2055)\end{array}$ & $\begin{array}{c}-0.8425 * * * \\
(0.3061)\end{array}$ & $\begin{array}{l}-0.0993 \\
(0.2828)\end{array}$ & $\begin{array}{l}-0.1416 \\
(0.3607)\end{array}$ & $\begin{array}{c}0.0499 \\
(0.5785)\end{array}$ \\
\hline Richer & $\begin{array}{c}-0.5507 * * * \\
(0.1286)\end{array}$ & $\begin{array}{c}-0.4888 * * * \\
(0.1379)\end{array}$ & $\begin{array}{c}-0.6781 * * \\
(0.3408)\end{array}$ & $\begin{array}{c}0.1143 \\
(0.2225)\end{array}$ & $\begin{array}{c}0.1961 \\
(0.2477)\end{array}$ & $\begin{array}{l}-0.0404 \\
(0.5755)\end{array}$ \\
\hline Employed & $\begin{array}{c}0.2200 \\
(0.1363)\end{array}$ & $\begin{array}{c}0.1297 \\
(0.1863)\end{array}$ & $\begin{array}{l}0.4281 * * \\
(0.2095)\end{array}$ & $\begin{array}{l}-0.0848 \\
(0.2072)\end{array}$ & $\begin{array}{l}-0.2740 \\
(0.2941)\end{array}$ & $\begin{array}{c}0.1483 \\
(0.3001)\end{array}$ \\
\hline Age & $\begin{array}{c}0.1772 * * * \\
(0.0320)\end{array}$ & $\begin{array}{c}0.1721 * * * \\
(0.0472)\end{array}$ & $\begin{array}{c}0.1734 * * * \\
(0.0448)\end{array}$ & $\begin{array}{c}0.1508 * * \\
(0.0623)\end{array}$ & $\begin{array}{c}0.1768 \\
(0.1073)\end{array}$ & $\begin{array}{l}0.1341 * \\
(0.0718)\end{array}$ \\
\hline Age square & $\begin{array}{c}-0.0022 * * * \\
(0.0005)\end{array}$ & $\begin{array}{c}-0.0021 * * * \\
(0.0007)\end{array}$ & $\begin{array}{c}-0.0022 * * * \\
(0.0007)\end{array}$ & $\begin{array}{c}-0.0019 * * \\
(0.0009)\end{array}$ & $\begin{array}{l}-0.0022 \\
(0.0016)\end{array}$ & $\begin{array}{l}-0.0017 \\
(0.0011)\end{array}$ \\
\hline Health insured & $\begin{array}{c}-0.2986 * * * \\
(0.0967)\end{array}$ & $\begin{array}{c}-0.6308 * * * \\
(0.1398)\end{array}$ & $\begin{array}{c}0.0215 \\
(0.1265)\end{array}$ & & & \\
\hline Relationship to head & $\begin{array}{l}0.1905 * \\
(0.0994)\end{array}$ & $\begin{array}{c}0.2210 \\
(0.1376)\end{array}$ & $\begin{array}{c}0.1410 \\
(0.1509)\end{array}$ & & & \\
\hline Pregnant & & & & $\begin{array}{c}-0.4864 * * \\
(0.2327)\end{array}$ & $\begin{array}{l}-0.6831 * \\
(0.3681)\end{array}$ & $\begin{array}{l}-0.3786 \\
(0.3153)\end{array}$ \\
\hline Urban & $\begin{array}{l}-0.1461 \\
(0.1577)\end{array}$ & & & $\begin{array}{l}-0.4530 * \\
(0.2417)\end{array}$ & & \\
\hline Constant cut 1 & & & & $\begin{array}{l}1.8042 * \\
(1.0481)\end{array}$ & $\begin{array}{c}2.1415 \\
(1.7559)\end{array}$ & $\begin{array}{c}1.8038 \\
(1.2817)\end{array}$ \\
\hline Constant cut 2 & & & & $\begin{array}{c}3.5610^{* * * *} \\
(1.0503)\end{array}$ & $\begin{array}{c}3.9160 * * \\
(1.7651)\end{array}$ & $\begin{array}{c}3.5789 * * * \\
(1.2718)\end{array}$ \\
\hline Constant cut 3 & & & & $\begin{array}{c}5.3625 * * * \\
(1.0311)\end{array}$ & $\begin{array}{c}5.5837 * * * * \\
(1.6722)\end{array}$ & $\begin{array}{c}5.4533 * * * \\
(1.2851)\end{array}$ \\
\hline Constant & $\begin{array}{c}-4.3578 * * * * \\
(0.5038)\end{array}$ & $\begin{array}{c}-4.9790 * * * \\
(0.7100)\end{array}$ & $\begin{array}{c}-4.2748 * * * * \\
(0.7269)\end{array}$ & & & \\
\hline Observations & 4,854 & 2,140 & 2,714 & 946 & 355 & 591 \\
\hline F-statistic & $\begin{array}{l}12.08 * * * \\
(0.000)\end{array}$ & $\begin{array}{l}7.89 * * * \\
(0.000)\end{array}$ & $\begin{array}{l}7.77 * * * * \\
(0.000)\end{array}$ & $\begin{array}{l}7.19 * * * \\
(0.000)\end{array}$ & $\begin{array}{l}3.55 * * * \\
(0.000)\end{array}$ & $\begin{array}{l}3.05 * * * \\
(0.001)\end{array}$ \\
\hline
\end{tabular}

\section{Discussion}

\subsection{Correlates of Alcohol Consumption}

Generally, the results suggest that the probability of consuming alcohol is influenced by some background characteristics. Firstly, the results show that women with primary and secondary education only in urban areas of Ghana have higher propensity to consume alcohol compared to their counterparts with no formal education (reference group). The plausible explanation for this finding is that lower levels of education (primary and secondary education) in urban areas are associated with low wage employments. Thus, while those with no formal education will be content with low paying jobs, frustration might influence those with relatively high formal education who end up in low-paying jobs to consume alcohol. Conversely, women resident in rural areas with secondary education are less likely to consume alcohol compared with those with no formal education. In this regard, the importance of female education in the probability to consume alcohol may be attributed to the fact that educated women are more likely to appreciate the negative 
consequences associated with alcohol consumption. While it is possible that the frustration effect of not being highly educated outweighs the negative implications effect in urban Ghana, the latter is likely to outweigh the former in rural Ghana also because not much education is required by rural women to get them employed in nonfarm wage employments. The finding for women resident in rural areas of Ghana is in line with Grossman (1972) that education improves the stock of knowledge of people and they are able to make decisions that have positive influence on their health. This is in contrast with Tampah-Naah and Amoah (2015) who found education as an insignificant variable influencing alcohol consumption among Ghanaian women.

The current study however reveals that some education categories in urban and rural Ghana significantly influence alcohol consumption decisions.

But for the poorest category, all the categories of wealth used in the study emerged significant in determining the probability of a woman's consumption of alcohol. Using the richest category as reference, the results from the full sample suggest that women in the $2^{\text {nd }}$ to $4^{\text {th }}$ quintiles are less likely to consume alcohol. Though the $2^{\text {nd }}$ to $4^{\text {th }}$ quintiles of wealth in the rural subsample are reported to be significant, the $2^{\text {nd }}$ wealth quintile is insignificant in the urban subsample. This suggests that the effect of wealth on alcohol consumption among women in rural Ghana is more intense. However, while the higher quintiles $\left(3^{\text {rd }}\right.$ and $\left.4^{\text {th }}\right)$ are highly significant at 1 percent level for the urban subsample, the $3^{\text {rd }}$ quintile is the most highly significant category for the rural subsample, also significant at 1 percentage level. This suggests that though higher wealth in urban areas is associated with alcohol consumption, lower wealth is much more associated with alcohol consumption in rural areas. The findings further suggest that the factors that motivate Ghanaian women to consume alcohol vary from urban to rural areas. A probable reason for this finding is that affordability may play a role in a woman's decision to consume alcohol or not. Also, plausibly linked to affordability, though insignificant, rural women who are employed are reported to be more likely to consume alcohol. The positive relationship between alcohol consumption and being employed is supported by Dawson et al (2005) and Chung et al. (2007).

The results from the study also revealed that age significantly affects alcohol consumption of women in both rural and urban areas. A year's increase in age, increases the propensity to consume alcohol by women in urban and rural areas. However, based on the negative sign on the age square variable (which is highly significant at 1 percentage level), as the woman further advances in age, she is less likely to consume alcohol in both urban and rural areas. This is probably 
due to the fact that older women are aware of their reduced health stock and the dangers associated with consuming alcohol, and so their probability to consume alcohol may be lower than their younger women counterparts. This finding is at variance with O'Malley and Wagenaar (1990) and Kacapyr and Choudhury (2006) whose studies did not find support for the influence of age in alcohol consumption.

Similarly, it is likely that because women who purchase health insurance policies are comparatively more health conscious, they are less likely to consume alcohol. The study finds that women in urban Ghana who own health insurance policies are less likely to consume alcohol. Conversely, their counterparts in rural areas are more likely to consume alcohol. Although insignificant, this could result from the negative moral hazard effect of owning a health insurance policy.

Finally, women who were heads of their households are revealed to have a higher probability to consume alcohol than their counterparts who were not household heads, albeit this variable is statistically significant at 10 percentage level for the full sample only. This may not be very surprising given that being a household head may imply her ability to afford the drink and also being a household head could mean she is not accountable to anyone in the household and so will have a higher probability to consume alcohol compared to their counterparts who do not head their households.

\subsection{Correlates of the Frequency of Alcohol Consumption}

Of the educational attainment categories, while secondary education attainment negatively and significantly affected the drinking frequency of urban women, primary education attainment positively and significantly influenced the drinking frequency of rural women. Also, in terms of the wealth quintiles, the poorer category was found to be significant in explaining the frequency of alcohol consumption. Relative to the richest category, women in the poorer category were found to be more likely to increase the frequency or quantities of alcohol consumed. This is highly significant at 1 percentage level and 5 percentage level in the full sample and rural subsample respectively. This revelation that poorer women in rural areas are more likely to consume greater quantities of alcohol than their counterparts in the richest category raises serious development and

public health concerns. The results show that if age increases by a year, women have a higher propensity to consume greater quantities of alcohol. Finally, pregnant women and women who 
resided in urban areas were revealed to be less likely to increase the frequency of alcohol consumption relative to their counterparts who were not pregnant and those who resided in rural areas respectively.

\section{Conclusion and Policy Recommendations}

This paper sought to identify the correlates of alcohol consumption among Ghanaian women (between 15 and 49 years) in addition to the frequency of consumption relying on data provided by the 2008 GDHS.

The study reveals that alcohol consumption among women in urban and rural Ghana was influenced by age, education, and wealth status. Although health insurance ownership is reported to affect alcohol consumption decisions of urban women, employment status significantly affects the alcohol consumption decisions of rural women. Moreover, the frequency of alcohol consumption among women of child bearing age in Ghana is found to be influenced by age, place of residence, pregnancy status, wealth, and education. The significance of these variables varied by place of residence. The study revealed that women without health insurance policies in urban Ghana, those with primary and secondary education in urban Ghana, females with no formal education in rural Ghana, and those employed in rural Ghana have higher probabilities to consume alcohol. The implication is that an effective alcohol policy should probably focus more on uninsured urban residents, women with primary and secondary education in urban areas, those with no formal education, as well as employed women resident in rural areas. In other words, more awareness about the dangers associated with the abuse of alcohol should be embarked among these women.

On the correlates of alcohol drinking frequency, the results from the ordered logit regression indicates that whereas pregnancy status, and secondary education attainment correlate with alcohol drinking frequency among women resident in urban areas, the correlates of alcohol drinking frequency among rural Ghanaian women are respondent's age, attainment of primary education, and wealth status. As policy measure, this current paper reveals the need for policies designed to reduce alcohol consumption among poor women resident in rural areas since this is likely not to affect the women only, but their families as well. Despite the smallness of the sample used in exploring the correlates of alcohol consumption frequency among Ghanaian women, the study 
modestly contributes to policy as well as existing literature. Further study should therefore be based on relatively larger samples.

\section{References:}

Adeyiga, G., Emilia, A., Udofia, E. A. and Yawson, A. E. 2014. "Factors Associated with Alcohol Consumption: A Survey of Women Childbearing at a National Referral Hospital in Accra, Ghana." African Journal of Reproductive Health 18(2):152-165.

Adusi-Poku, Y. 2011. "Pregnant Women and Alcohol use in the Bosomtwe District of the Ashanti Region". Thesis Submitted to the Department of Community Health, KNUST, Kumasi.

Anyawie, M. 2013. "Factors Affecting Alcohol Use among Women in Ghana." Unpublished MA Thesis, Regional Institute for Population Studies, University of Ghana.

Barros, M. B. A., Botega, N. J., Dolgala-Prondo, P., Marin-Leon, L. and Oliveira, H. B. 2007. "Prevalence of Alcohol Abuse and Associated Factors in a Population-based Study." Rev Saude Publica 41(4):502-509.

Brown, T. L., Parks, G. S. and Zimmerman, R. S. 2001. "The Role of Religion in Predicting Adolescents' Alcohol Use and Problem Drinking.” Journal of Studies on Alcohol 62(5):696-705.

Cheah, Y. K. and Rasiah, R. 2017. "Analysis of the Determinants of Alcohol Consumption among Adult Males in Malaysia." Journal of Health Management (19)1:28-38.

Kim, W. and Kim, S. 2008. "Women's Alcohol Use and Alcoholism in Korea." Substance Use and Misuse 43(89):1078-1087.

Dawson, D. A., Grant, B. F. and Ruan, W. J. 2005. "The Association between Stress and Drinking: Modifying Effects of Gender and Vulnerability." Alcohol and Alcoholism 40(5):453-460.

Ghana Statistical Service (GSS), Noguchi Memorial Institute for Medical Research (NMIMR), \& ORC Macro. 2009. Ghana Demographic and Health Survey 2008. Calverton, Maryland: GSS, NMIMR, and MI.

Grossman, M. 1972. "On the Concept of Health Capital and the Demand for Health.” Journal of Political Economy 80(2):223-249.

Kacapyr, E. and Choudhury, S. 2006. "Determinants of Alcohol Consumption by College Students." Economic Review 37:3-19.

Luginaah, I. and Dakubo, C. 2003. "Consumption and Impacts of Local Brewed Alcohol (akpeteshie) in the Upper West Region of Ghana. A Public Health Tragedy.” Social Science and Medicine 57:1747-1760.

Martinez P., Røislien J., Naidoo N. and Clausen, T. 2011. "Alcohol Abstinence and Drinking among African Women: Data from the World Health Surveys." BMC Public Health 11: 160.

McDermott, R., Campbell, S., Ming, L. and McCulloch, B. 2009. "The Health and Nutrition of Young Indigenous Women in North Queensland - Intergenerational Implications of Poor Food Quality, Obesity, Diabetes, Tobacco Smoking and Alcohol Use.” Public Health Nutrition 12 (11):2143-2149.

O’Malley, P. M. and Wagenaar, A. C. 1991. "Effects of Minimum Drinking Age Laws on Alcohol Use, Related Behaviors and Traffic Crash Involvement among American Youth: 1976-1987." Journal of Studies on Alcohol and Drug 52(5) [Online]. 
Available:www.collegedrinkingprevention.gov/supportingresearch/journal/wagenaar.aspx [Accessed 2014, April 2]

Newbury-Birch, D., Walker, J., Avery, L., Beyer, F., Brown, N., Jackson, K. and Lock, C. A. 2009. "Impact of Alcohol Consumption on Young People, A Systematic Review of Published Reviews”. Institute of Health and Society at Newcastle University: Department for Children, Schools and Families.

Perkings, H. W. 2002. "Surveying the Damage: A Review of Research on Consequences of Alcohol Misuse in College Populations." Journal of Studies on Alcohol and Drugs, Supplement 14:91-100.

World Health Organization. 2011. “Global Status Report on Alcohol and Health.” [Online]. Available: www.who.int/substance_abuse/publications/global_alcohol_report/msbgsruprofile.pdf [Accessed 2014, March 20].

Rintaugu, E. G., Andanje, M. and Amusa, L. O. 2012. "Socio-Demographic Correlates of Alcohol Consumption among University Athletes.” African Journal for Physical, Health Education, Recreation and Dance 18(4):

Seaman, P., \& Ikegwuonu, T. 2010. “Drinking to Belong: Understanding Young Adults' Alcohol Use within the Social Networks.” Joseph Rowntree Foundation. Glasgow. [Online]. Available: http://www.jrf.org.uk/publications/young-people-alcohol-influences-drinking [Accessed 2014, March 15].

Tampah-Naah, A. M. and Amoah, S. T. 2015. "Consumption and Drinking Frequency of Alcoholic Beverage among Women in Ghana: a Cross-sectional Study.” BMC Public Health 15:1. 